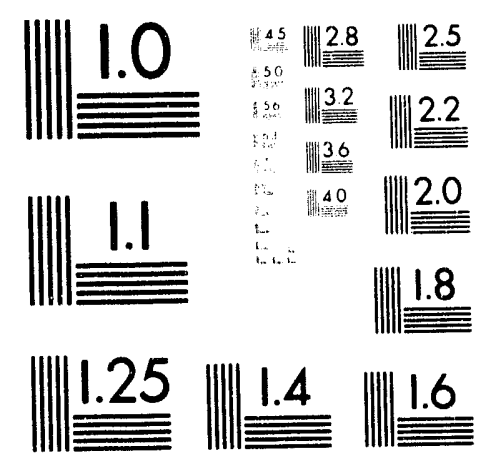



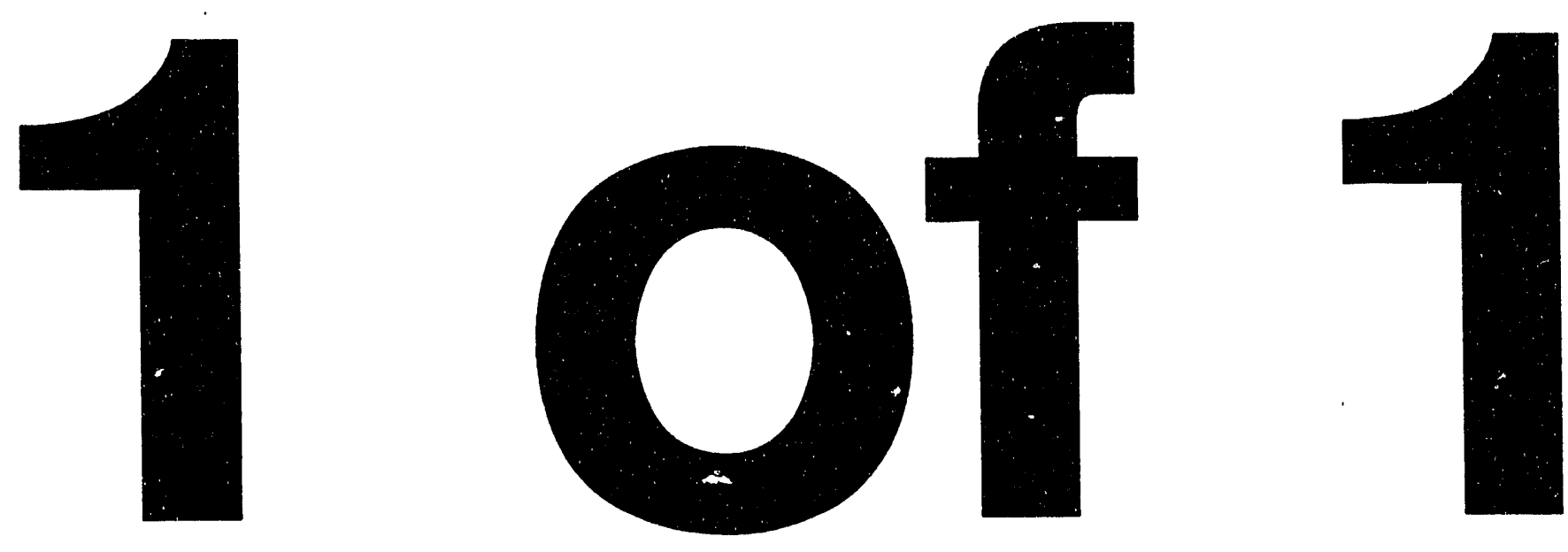
DOE/PCP2545-3

\title{
FISCHER-TROPSCH SYNTHESIS IN SUPERCRITICAL FLUIDS
}

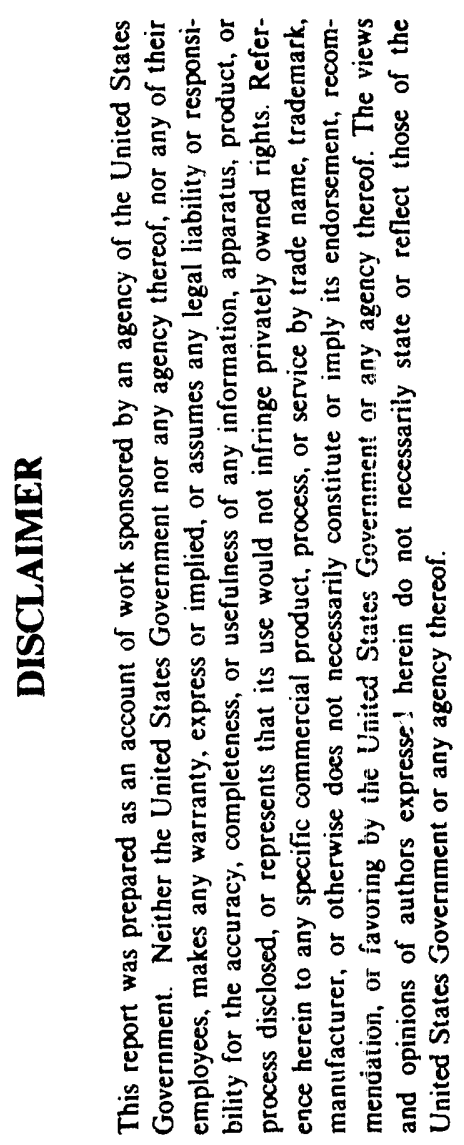

\author{
QUARTERLY TECHNICAL PROGRESS REPORT
}

April 1,1993 - June 30, 1993

\section{Principal Investigators}

Aydin Akgerman

Dragomir B. Bukur

Texas A\&M University

Department of Chemical Engineering

College Station, Texas 77843-3122

July 29, 1993

Organization

Texas Engineering Experiment Station 308 Wisenbaker Engineering Research Center College Station, TX 77843-3124

Prepared for the Pittsburgh Energy Technology Center, the United States Department of Energy Under Grant No. DE-FG22-92PC92545

“U.S. Department of Energy Patent Clearance not required

prior to publication of this document" 


\section{Objectives for the Third Quarter, Year 1}

Our objectives during the third quarter were to modify the Taylor Dispersion Apparatus so that propane or a similar hydrocarbon gas could be utilized as a solvent, and estimate supercritical properties of reaction mixture under typical process conditions in different solvents (propane, butane and hexane).

\section{Accomplishments, Third Quarter, Year 1:}

\section{A. Diffusion Measurements}

We have completed modifications of the Taylor Dispersion Apparatus so that propane can be used as a solvent. Problems were encountered initially compressing propane to the necessary pressures because of cavitation in the liquid pump. This problem was overcome by placing a check valve in the line after the pump and pressures of 2500 psi have been achieved. The system has been pressure tested by using a soap solution on exposed joints and performing a mass balance (leak test). The mass balance was made by reading the volumetric flow rate of liquid in the syringe pump and converting this to expected gas flow rate. The liquid was then vaporized and a dry gas meter measured the amount of gas at the exit of the apparatus. The expected and measured gas flow rates were in excellent agreement, indicating that there are no significant leaks in the system.

Presently, we are having problems with the use of UV detection for the diffusing compounds. The detector is successfully auto-zeroing with a blank cell and with $\mathrm{CO}_{2}$. With the use of instrument grade propane, however, the detector is unable to auto-zero because of absorption of unknown impurity. We believe this problem is caused by a sulfur compound in the propane gas cylinder and we plan to install an active carbon guard bed to remove a sulfur containing compounds. After we are successful in zeroing the UV detector, we will determine the optimal wavelengths for the detection of 
olefins in the UV range. The initial data may necessitate further changes in the design of the apparatus.

We have completed a safety report for the above apparatus, which has been approved by the Chemical Engineering Department Safety Committee. This report contains MSDS for chemicals which will be used in experiments, descriptions of worst case scenario for accidents and experimental operating procedures.

\section{B. Fischer - Tropsch Reaction Related Studies \\ a. Experimental Set - Up}

We have received a temperature probe assembly made by Omega according to our design specifications. The temperature probe consists of six thermocouples placed inside an $1 / 8$ inch thermowell, which will be placed inside the reactor to measure axial temperature profile during Fischer - Tropsch synthesis. During the reportirig period we have received a flammable gas detector unit, which will be installed near the reactor.

\section{b. Estimation of Critical Properties of Reaction Mixture}

We have reviewed several literature references for calculating supercritical properties (temperature, pressure and density) of mixtures. The methodology adopted is based on the work by Anselme and Teja (AIChE Jl., Vol 36, 897 - 906, 1990), and the use of Soave - Redlich - Kwong (SRK) equation of state (EOS).

Composition of reaction mixture was calculated using Anderson-Schultz-Flory formula to estimate the hydrocarbon product distribution, assuming $\mathrm{CO}$ conversion of $85 \%, \mathrm{CO}$ conversion to $\mathrm{CO}_{2}$ of $50 \%$, and using reaction stoichiometry from our previous tests in fixed bed reactors. Densities of reaction mixture for various potential solvents (propane, $n$-butane and $n$-hexane) were calculated at one set of process conditions, namely: $250{ }^{\circ} \mathrm{C}, 68.8$ bar (1000 psig) and feed molar composition of $\mathrm{C}_{3} \mathrm{H}_{8}$ : $\mathrm{CO}: \mathrm{H}_{2}=80: 12: 8$. The formulas proposed by Anselme and Teja were used to calculate the critical temperature and volume of the mixture. Calculation of the critical volume of the mixture was accomplished by using calculated value of the critical 
volume of pure solvent as a starting point instead of the measured critical volume as outlined in Anselme and Teja's paper. The former was calculated by using a SRK compression factor $z_{c}=0.33$. The critical pressure of the mixture was then calculated from the SRK EOS. Lee-Kesler formulas (Lee, B. I. and Kesler, M. G., AIChE J., Vol. 21, $510-527,1975)$ were then used to determine a compression factor at our operating conditions and the calculation of mixture densities for the various solvents followed.

The results of these calculations are summarized in Table 1. These preliminary results reveal the following. Values of the critical temperature of the reaction mixture are significantly smaller than the corresponding values of pure solvents (Table 2). The critical pressures of the reaction mixture are smaller than the critical pressure of pure solvents, for propane and butane, but the opposite is true for hexane mixtures. The density of reaction mixture at operating conditions increases with the molecular weight of the solvent (Table 1). At the chosen set of operating conditions, the reaction mixture is in a supercritical region for all three types of solvents. Additional calculations of this type are needed to assess the effect of operating conditions and sensitivity to product composition on the density of the reaction mixture and/or critical properties.

\section{c. Sulfur Removal from Propane}

This problem was discussed briefly in the last quarterly report. The catalyst for sulfur removal (Carasorb $\mathrm{Co}$ ) is capable of removing $0.022 \mathrm{lb}$ of hydrogen sulfide per ib of catalyst. In order to decrease the sulfur level in the propane from $1 \mathrm{ppm}$ (maximum amount in the instrument grade propane) to $0.05 \mathrm{ppm}$ (to prevent catalyst deactivation by sulfur poisoning) one would need $7.5 \mathrm{lbs}$ of catalyst during a $300 \mathrm{~h}$ Fischer - Tropsch synthesis test. This would require the use of a large guard bed, which is fairly expensive and introduces a large dead volume in the system. We plan to look into this problem further (alternative solvents, catalysts for sulfur removal) before selecting the supercritical fluid for reaction experiments. 


\section{Plans for the Fourth Quarter, Year 1}
A. Diffusion Measurements

We vill determine the optimal wavelengths for detection of olefins in the UV range. Modifications to the apparatus will be completed and experimental measurements of diffusion coefficients of various olefins will be initiated.

\section{B. Reaction Related Studies}

1. The safety report for experimental apparatus will be completed and submitted for approval; 2. The solvent and catalyst for sulfur removal will be selected; 3 . The temperature probe and the flammable gas detector will be installed and tested; 4 . Fischer - Tropsch experiments at standard conditions $\left(250^{\circ} \mathrm{C}, 200 \mathrm{psig}, \mathrm{H}_{2} \mathrm{CO}=0.7\right)$, i.e. not under supercritical conditions, will be initiated to test the newly designed fixed bed reactor apparatus. 
Table 1: Critical Properties of Reaction Mixtures

\begin{tabular}{|l|l|l|l|l||}
\hline Solvent & $T_{c}{ }^{\text {mix }}(\mathrm{K})$ & $\mathrm{P}_{\mathrm{c}}^{\text {mix }}(\mathrm{bar})$ & $\rho_{\mathrm{c}}{ }^{\text {mix }}\left(\mathrm{g} / \mathrm{cm}^{3}\right)$ & $\rho^{\text {mix }}\left(\mathrm{g} / \mathrm{cm}^{3}\right)^{*}$ \\
\hline Propane & 297.43 & 36.88 & .233 & .0748 \\
\hline Butane & 270.70 & 35.62 & .251 & .110 \\
\hline Hexane & 237.29 & 31.23 & .335 & .249 \\
\hline
\end{tabular}

*at operating conditions of $523 \mathrm{~K}$ and $68.82 \mathrm{bar}$

Table 2: Critical Properties of Pure Solvents

\begin{tabular}{|l|l|l|l||}
\hline Solvent & $\mathrm{T}_{\mathrm{c}}(\mathrm{K})$ & $\mathrm{P}_{\mathrm{c}}(\mathrm{bar})$ & $\rho_{\mathrm{c}}\left(\mathrm{g} / \mathrm{cm}^{3}\right)$ \\
\hline Propane & 369.8 & 42.5 & .217 \\
\hline Butane & 425.2 & 38.0 & .228 \\
\hline Hexanc & $j 07.4$ & 29.7 & .232 \\
\hline
\end{tabular}



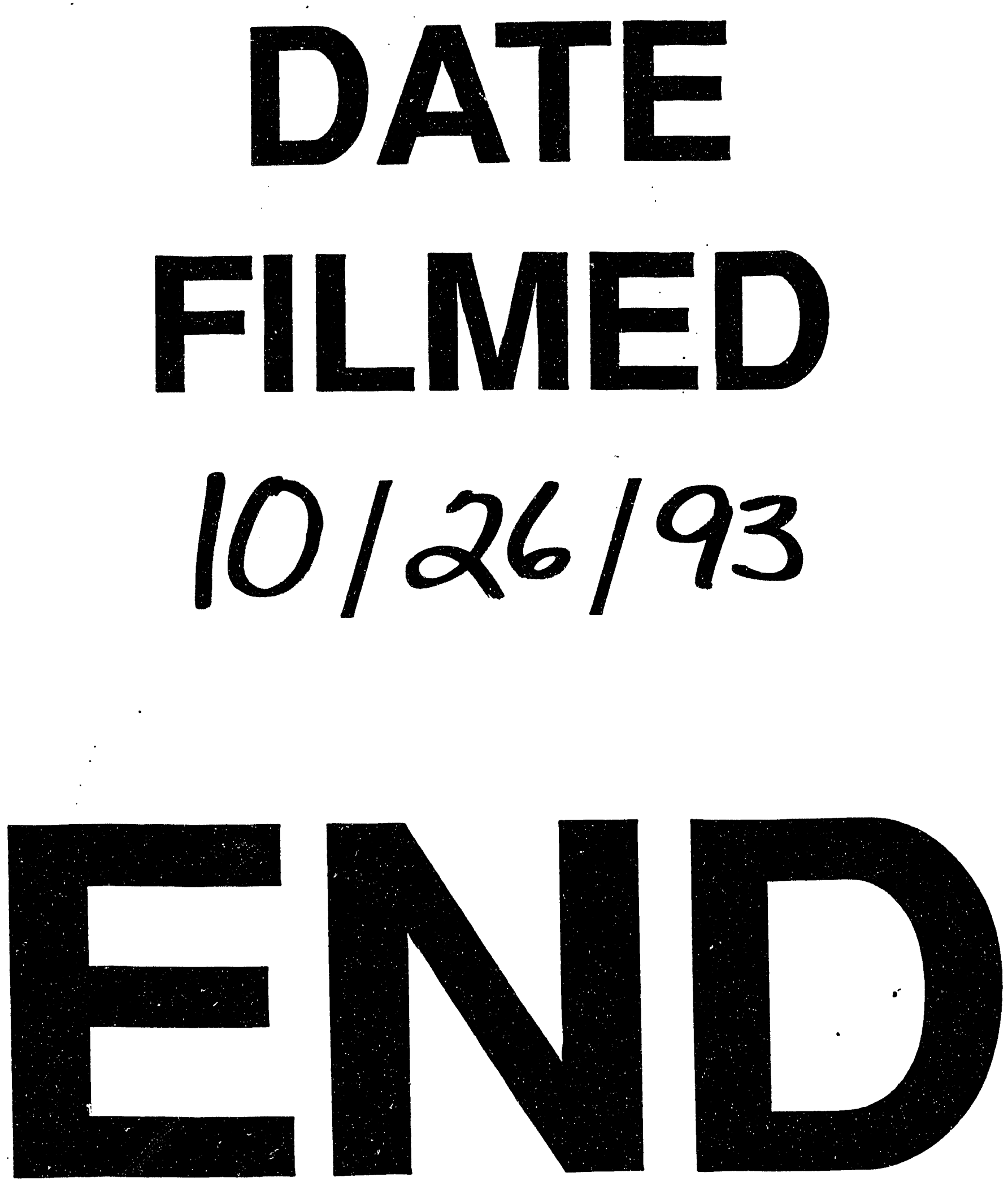
